\title{
PERANCANGAN TATA LETAK LAPANGAN PENUMPUKAN PETI KEMAS (STUDI KASUS: PELABUHAN SORONG)
}

\section{CONTAINER YARD LAYOUT DESIGN (STUDY CASE: PORT OF SORONG)}

\author{
Gita Kurnia ${ }^{\text {a, }{ }^{*} \text {, Adi Kurnia Prasetiyono }}{ }^{\text {a,2 }}$, Andika Mochamad Refiawan a,3, Marlene \\ Hibatullah $^{\text {a,4 }}$, Ferani Eva Zulvia ${ }^{\text {a,5 }}$ \\ a Teknik Logistik, Universitas Pertamina, Jalan Teuku Nyak Arief, Kebayoran Lama, Jakarta, Indonesia \\ 1*gita.kurnia@ universitaspertamina.ac.id, ${ }^{2}$ adikurniaprasetiyono@gmail.com, ${ }^{3}$ andikarefiawan@ @mail.com, \\ 4 marlenehibatullahh@gmail.com,${ }^{5}$ feranieva.z@ universitaspertamina.ac.id
}

\section{ABSTRACT}

Port of Sorong plays an important role in the export-import container activities especially for West Papua Province. Based on initial observation, the current operations in the container terminal of Sorong Port have not run efficiently due to inefficient layout of its container yard. Therefore, this study aims to propose a new container yard layout for Sorong Port. The proposed layout is designed based on future demands and relations among container activities in the terminal. This study applies forecasting methods to forecast the future numbers of inbound and outbound containers handled at Sorong Port and to determine the capacity requirement of the container yard. The performance of the proposed layout is evaluated based on the Yard Occupancy Ratio (YOR). As result, the proposed layout will be able to accommodate Sorong Port's demand with good performance of YOR value of 71,03\% in 2025.

Keywords : Facility Layout, Port Operations, Container Terminal, Container Handling, Yard Occupancy Ratio

\begin{abstract}
ABSTRAK
Pelabuhan Sorong memegang peranan penting dalam kegiatan ekspor dan impor peti kemas khususnya di wilayah provinsi Papua Barat. Berdasarkan observasi di lapangan, kegiatan operasional di terminal peti kemas Pelabuhan Sorong belum berjalan dengan efisien karena tata letak lapangan penumpukannya belum dirancang dengan teratur. Oleh karena itu, penelitian ini bertujuan untuk memberikan usulan tata letak lapangan penumpukan untuk Pelabuhan Sorong. Usulan tata letak dirancang berdasarkan hubungan antara aktivitasaktivitas pergerakan peti kemas di terminal dan ramalan permintaan peti kemas. Penelitian ini menerapkan metode peramalan untuk meramalkan jumlah peti kemas impor dan ekspor serta mengidentifikasi jumlah kapasitas yang dibutuhkan lapangan penumpukan. Hasil rancangan dari usulan tata letak dievaluasi utilitasnya menggunakan rumus Yard Occupancy Ratio (YOR). Berdasarkan perhitungan, usulan rancangan tata letak lapangan penumpukan dapat mengakomodir jumlah permintaan peti kemas Pelabuhan Sorong dengan nilai YOR yang mendekati standar kinerja pelabuhan yaitu $71,03 \%$ pada tahun 2025 .
\end{abstract}

Kata kunci : Tata Letak Fasilitas, Operasi Pelabuhan, Terminal Peti Kemas, Penanganan Peti Kemas, Utilitas Pelabuhan

Judul Artikel: Perancangan Tata Letak Lapangan Penumpukan Peti Kemas (Studi Kasus:

Pelabuhan Sorong) 


\section{A. Pendahuluan}

Pelabuhan Sorong merupakan sebuah pelabuhan yang berlokasi di daerah timur Indonesia dan memiliki peran penting sebagai gerbang perekonomian di wilayah Provinsi Papua Barat khususnya untuk daerah-daerah seperti Kota Sorong, Kabupaten Sorong, Kabupaten Sorong Selatan, Kabupaten Raja Ampat, Kabupaten Tambraw, dan Kabupaten Maybrat. Pelabuhan ini menjadi salah satu pusat aktivitas ekspor dan impor barang ataupun pertukaran barang pada Provinsi Papua Barat. Pelabuhan Sorong memiliki fasilitas penunjang yang dapat memenuhi kegiatan operasional kapal penumpang, kapal peti kemas, dan kapal pesiar yang bersandar pada Pelabuhan Sorong. Sebagai pintu gerbang kegiatan ekspor dan impor di daerah Timur Indonesia, Pelabuhan Sorong harus memiliki fasilitas yang menunjang agar kegiatan operasional di pelabuhan dapat berjalan dengan lancar. Salah satu fasilitas yang penting adalah lapangan penumpukan peti kemas. Fasilitas ini berfungsi sebagai tempat meletakan dan menumpuk peti kemas sebelum dan sesudah dilakukan proses bongkar muat dari dan menuju kapal (Somadi, Permatasari, \& Chintia, 2020).
Saat ini, Pelabuhan Sorong telah memiliki lapangan penumpukan. Akan tetapi, berdasarkan hasil observasi, kondisi lapangan penumpukan yang ada saat ini belum ideal. Gambar 1 menunjukkan ilustrasi tata letak di Pelabuhan Sorong. Beberapa permasalahan yang biasa terjadi di lapangan penumpukan saat ini di antaranya adalah peti kemas dapat diletakkan dimana saja, belum adanya pengaturan baris, dan lajur kendaraan yang belum tertata. Selain itu, data historis lalu lintas peti kemas di Pelabuhan Sorong menunjukkan adanya tren peningkatan. Gambar 2 dan 3 menunjukkan tren kenaikan lalu lintas peti kemas di Pelabuhan Sorong dari tahun 2011 sampai dengan 2018.

Peningkatan lalu lintas peti kemas berkaitan erat dengan kapasitas lapangan penumpukan. Idealnya, lapangan penumpukan harus dapat memenuhi kebutuhan sesuai dengan lalu lintas peti kemas di pelabuhan tersebut. Oleh karena itu, Pelabuhan Sorong harus segera membenahi tata letak lapangan penumpukan agar tidak menimbulkan permasalahan di masa depan khususnya terkait keterbatasan area lapangan penumpukan. 


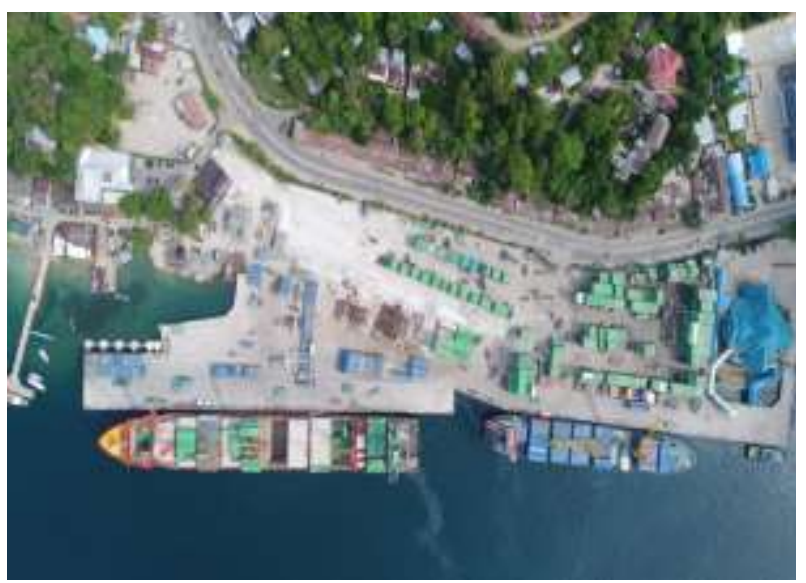

Gambar 1. Pelabuhan Sorong

Sumber: PT Pelabuhan Indonesia IV

Cabang Sorong (2020)

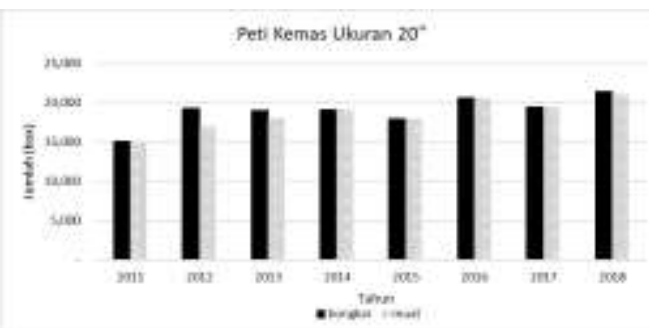

Gambar 2. Data Lalu Lintas Peti Kemas

Ukuran 20 Feet Di Pelabuhan Sorong

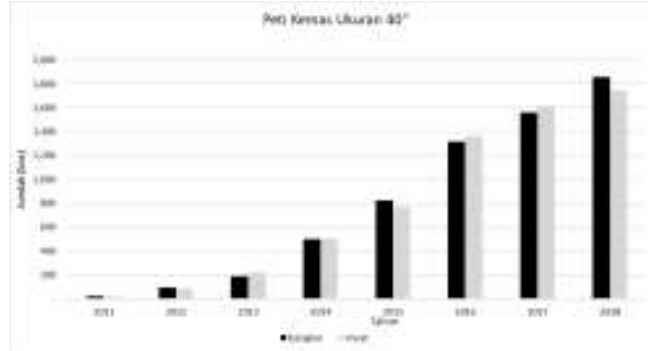

Gambar 3. Data Lalu Lintas Peti Kemas

\section{Ukuran 40 Feet Di Pelabuhan Sorong}

Untuk menyelesaikan permasalahan di atas, penelitian ini bertujuan untuk merancang tata letak Pelabuhan Sorong, khususnya tata letak lapangan penumpukan peti kemas yang dapat memenuhi kebutuhan Pelabuhan Sorong di masa depan.

Proses perancangan tata letak lapangan penumpukan peti kemas di Pelabuhan Sorong dimulai dengan observasi lapangan dan identifikasi kebutuhan. Untuk mengantisipasi kondisi di masa depan, penelitian ini juga melakukan peramalan lalu lintas peti kemas sampai dengan tahun 2030.

Untuk dapat memenuhi kebutuhan sampai dengan tahun 2030, perancangan tata letak dilakukan berdasarkan hasil peramalan. Selanjutnya, tata letak yang direkomendasikan dievaluasi berdasarkan nilai Yard Occupancy Ratio (YOR). Hasil dari penelitian ini diharapkan dapat membantu Pelabuhan Sorong untuk mengatasi permasalahan akibat tata letak di pelabuhan yang kurang ideal khususnya di lapangan penumpukan peti kemas. Selain itu, tata letak yang diusulkan diharapkan dapat membantu pelabuhan untuk memenuhi kebutuhan fasilitas kegiatan ekspor dan impor di Pelabuhan Sorong.

a. Studi Literatur Lapangan Penumpukan Peti Kemas

Menurut (B. J. B. O. Y. Triatmodjo, 2010), lapangan penumpukan peti kemas merupakan area penumpukan peti kemas yang berisi muatan peti kemas penuh (Full Container Load) 
dan peti kemas kosong (empty container) yang akan dikapalkan. Lapangan ini terletak di daratan dan permukaannya harus diberi dukungan fungsi agar bisa mendukung beban peti kemas dan peralatan pengangkat juga pengangkut. Lapangan penumpukan berfungsi untuk menyimpan barangbarang berat dan besar serta mempunyai ketahanan terhadap panas matahari dan hujan.

Barang-barang yang disimpan di lapangan penumpukan berupa kendaraan berat, barang-barang yang terbuat dari baja seperti tiang listrik, plat baja, baja profil, baja beton. Suatu lapangan penumpukan harus memenuhi persyaratan sebagai berikut:

1. Tersedianya tempat untuk area penyortiran barang harus dikembangkan setelah mempertimbangkan jenis dan jumlah barang yang ditangani serta kondisi penanganannya.

2. Lay out lapangan harus aman bagi operasi kendaraan dan peralatan pengangkut barang.

3. Area penyortiran barang harus dikeraskan dengan bahan untuk
4. pisan jalan / trotoar seperti beton semen atau beton aspal.

5. Area penyortiran barang harus dilengkapi dengan fasilitas pembuangan air.

6. Area penyortiran barang dimana pengangkutan barang dilakukan pada malam hari harus dilengkapi dengan penerangan yang memadai.

7. Pada area penyortiran barang yang berbahaya bagi umum, harus ada tanda / rambu larangan masuk untuk umum, dan areanya harus dikelilingi dengan pagar.

8. Pada area penyortiran barang dimana barang dapat diterbangkan oleh angin, maka harus dilengkapi dinding pelindung.

Perhitungan kebutuhan kapasitas lapangan penumpukan diperoleh dengan cara menghitung luas area penumpukan pada layout yang telah dibuat dengan rumus (1) sebagai berikut (Timur, 2016).

$$
A=\frac{\sum T E U^{\prime} S \times D T \times S f}{365 \times S t h \times(1-B S)}
$$

Judul Artikel: Perancangan Tata Letak Lapangan Penumpukan Peti Kemas (Studi Kasus: 
Dengan keterangan,

: Luas lapangan
$\quad$ penumpukkan $\left(\mathrm{m}^{2}\right)$

$\sum T E U^{\prime} S \quad$ : Total peti kemas yang bongkar dan muat dalam setahun (TEU)

DT : Dwelling Time (Hari)

Sf : Stowage factor $\left(\mathrm{m}^{3}\right)$

Sth : Tinggi tumpukan peti kemas

Bs : Broken Stowage factor

365 : Jumlah hari dalam setahun

Perhitungan tingkat pemakaian lapangan penumpukan atau YOR (Yard Occupancy Ratio) digunakan untuk mengukur performansi lapangan penumpukan dan mengukur apakah rancangan tata letak yang dibuat dapat memenuhi peti kemas yang harus ditempatkan pada lapangan penumpukan. Secara umum, YOR

b. Metode Peramalan

Peramalan merupakan salah satu metode yang digunakan untuk melakukan perencanaan produksi pada periode mendatang. Dengan melakukan peramalan maka permintaan akan suatu barang dapat terkendali dengan baik. Metode peramalan yang digunakan dapat dihitung berdasarkan jumlah peti kemas, dwelling time, dan kapasitas lapangan penumpukan peti kemas. Beberapa rumus yang dapat digunakan untuk menghitung YOR dapat dilihat pada rumus di Tabel 1.

Tabel 1. Rumus Perhitungan YOR

\begin{tabular}{ll}
\hline \multicolumn{1}{c}{ Rumus YOR } & \multicolumn{1}{c}{ Referensi } \\
\hline$Y O R$ & (Ariyanto, \\
$=\frac{(T E U) \text { barang } \times(\text { hari }) d \text { welling time }}{\text { kapasitas efektif lapangan penumpukan (TEU) }}$ &
\end{tabular}

$Y O R=\frac{\sum T E U^{\prime} \times D T}{\text { Kapasitas lapangan tersedia }} \times 100 \%$

(B.

Triatmodjo, 2011)

Dimana,

$Y O R$ : Tingkat pemakaian lapangan penumpukkan $(\%)$

$\sum T E U^{\prime}$ : Total peti kemas bongkar dan muat dalam setahun (TEU)

DT : Dwelling Time (Hari)

$Y O R=\frac{\text { Kapasitas lapangan terpakai }}{\text { Kapasitas lapangan tersedia }} \times 100 \%$

(Mappangara,

Samang, Adisasmita, \& Sitepu; Pakpahan, 2019)

Judul Artikel: Perancangan Tata Letak Lapangan Penumpukan Peti Kemas (Studi Kasus:

dalam penelitian ini adalah linear, exponential, quadratic, siklis, dan tren siklis untuk menentukan jumlah peti kemas yang dibongkar dan dimuat pada Pelabuhan Sorong dan pengambilan keputusan untuk menentukan metode yang akan digunakan adalah dengan melakukan 
dengan metode Mean Absolute

Percentage Error (MAPE), yaitu metode untuk mengetahui tingkat error dari metode yang digunakan. Linear adalah teknik optimasi untuk suatu sistem yang memiliki linear constraint dan fungsi tujuan yang linear. Tujuan dari metode ini adalah untuk menemukan nilai dari suatu variabel yang dapat memaksimalkan atau meminimalkan suatu fungsi tujuan. Metode siklis digunakan jika data yang dimiliki terdapat fluktuasi peningkatan dan penuruan secara berulang dengan periode waktu yang panjang. Tren Siklis digunakan ketika data yang dimiliki terdapat perubahan rata-rata secara teratur dalam jangka waktu yang panjang. Berikut adalah rumus perhitungan metode peramalan.

\section{Linear:}

$$
\hat{Y}(t)=\hat{a}+\widehat{b t}
$$

Quadratic:

$$
\widehat{Y}(t)=\hat{a}+\widehat{b t}+\hat{c} t^{2}
$$

\section{Exponential:}

$$
\widehat{Y}(t)=\hat{a} e^{b t}
$$

Siklis

$$
\begin{aligned}
\hat{Y}(t)=a+b \cos \frac{2 \pi t}{n} & \\
& +c \sin \frac{2 \pi t}{n}
\end{aligned}
$$

Tren Siklis

$$
\begin{aligned}
\hat{\mathrm{Y}}=a+b t+ & c \cos \frac{2 \pi t}{n} \\
& +c \sin \frac{2 \pi t}{n}
\end{aligned}
$$

MAPE adalah ukuran statistik untuk mengetahui tingkat akurasi suatu sistem peramalan. Ukuran akurasi yang dihasilkan berupa persentasi dan hasil tersebut dihitung sebagai rata-rata persen kesalahan untuk setiap periode. Berikut adalah rumus perhitungan MAPE.

$$
M A P E=\frac{1}{n} \sum_{t=1}^{n}\left|\frac{A_{t}-F_{t}}{A_{t}}\right|
$$




\section{B. Metode Penelitian}

Tahapan-tahapan dalam penelitian ini meliputi tahap observasi dan wawancara, pengumpulan data, identifikasi kebutuhan, peramalan lalu lintas peti kemas, dan perancangan tata letak. Gambar 4 menunjukkan tahapan-tahapan tersebut.

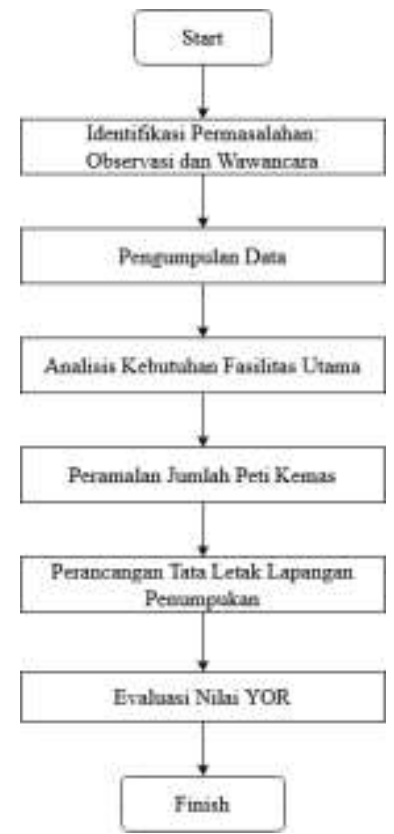

Gambar 4. Tahapan Metodologi Penelitian

a. Observasi dan Wawancara

Tahapan pertama yang dilakukan dalam penelitian ini adalah observasi dan wawancara. Tujuan dari tahap ini adalah untuk mengidentifikasi permasalahan yang ada di Pelabuhan Sorong khusunya terkait Lapangan
Penumpukan. Kegiatan observasi dilakukan selama bulan Mei dan Agustus 2019. Observasi lapangan yang dilakukan dalam penelitian ini mencakup observasi kegiatan bongkar, muat, stripping dan stuffing peti kemas. Untuk memvalidasi hasil observasi serta memahami permasalahan lebih lanjut, penelitian ini melakukan wawancara kepada beberapa orang karyawan di Pelabuhan Sorong.

b. Pengumpulan Data

Pengumpulan data yang dilakukan pada penelitian ini fokus pada data lalu lintas peti kemas di Pelabuhan Sorong, dengan menggunakan data historis dari tahun 2011 hingga 2018. Data yang dikumpulkan mencakup data-data sebagai berikut:

- Jumlah peti kemas berisi yang berukuran 20 feet yang dibongkar

- Jumlah peti kemas berisi yang berukuran 40 feet yang dibongkar

- Jumlah peti kemas kosong yang berukuran 20 feet yang dibongkar 
- Jumlah peti kemas kosong yang berukuran 40 feet yang dibongkar

- Jumlah peti kemas berisi yang berukuran 20 feet yang dimuat

- Jumlah peti kemas berisi yang berukuran 40 feet yang dimuat

- Jumlah peti kemas kosong yang berukuran 20 feet yang dimuat

- Jumlah peti kemas kosong yang berukuran 40 feet yang dimuat.

c. Analisis Kebutuhan Fasilitas Utama Tahapan analisis kebutuhan dilakukan untuk mengidentifikasi fasilitasfasilitas lain yang harus ada di pelabuhan. Tujuan dari identifikasi kebutuhan failitas utama ini adalah untuk menghitung luas area di Pelabuhan Sorong yang dapat digunakan sebagai lapangan penumpukan peti kemas. Sehingga, tata letak area penyimpanan peti kemas yang dihasilkan sudah mempertimbangkan fasilitas lain yang harus ada di pelabuhan tersebut.

d. Peramalan Jumlah Peti Kemas

Penelitian ini bertujuan untuk merancang tata letak lapangan penumpukan yang dapat memenuhi kebutuhan Pelabuhan Sorong di masa mendatang, setidaknya sampai dengan tahun 2030. Oleh karena itu, diperlukan peramalan jumlah peti kemas yang akan disimpan di lapangan penumpukan tersebut. Peramalan dilakukan untuk memprediksi jumlah peti kemas ukuran 20 feet dan 40 feet, berisi maupun kosong yang akan dibongkar ataupun dimuat. Proses peramalan dilakukan menggunakan metode peramalan siklis dan tren siklis. Hasil dari setiap metode peramalan akan dievaluasi berdasarkan nilai MAPE. Hasil peramalan dengan nilai MAPE terkecil yang akan digunakan untuk proses perancangan tata letak lapangan penumpukan.

\section{e. Perancangan Tata Letak Lapangan Penumpukan}

Perancangan tata letak pada lapangan penumpukan pada Pelabuhan Sorong dilaksanakan berdasarkan alur penanganan peti kemas di pelabuhan (Gambar 5). Pada Pelabuhan Sorong, peti kemas mengalami proses bongkar dari kapal kemudian disimpan di lapangan penumpukan bongkar, kemudian dikirim ke proses stripping dan stuffing. Apabila isi peti kemas dibongkar

(stripping) kemudian diisi kembali (stuffing), maka peti kemas akan masuk ke dalam lapangan penumpukan peti kemas muat dan langsung menunggu proses muat ke kapal lagi. Tetapi, apabila peti kemas

Judul Artikel: Perancangan Tata Letak Lapangan Penumpukan Peti Kemas (Studi Kasus: 
yang sudah melalui proses stripping hingga

kosong dan tidak diisi kembali, maka peti

kemas akan masuk ke dalam lapangan

penumpukan peti kemas empty dan

dilakukan pengecekan jika terdapat

customer yang ingin menggunakan peti

kemas tersebut kembali.

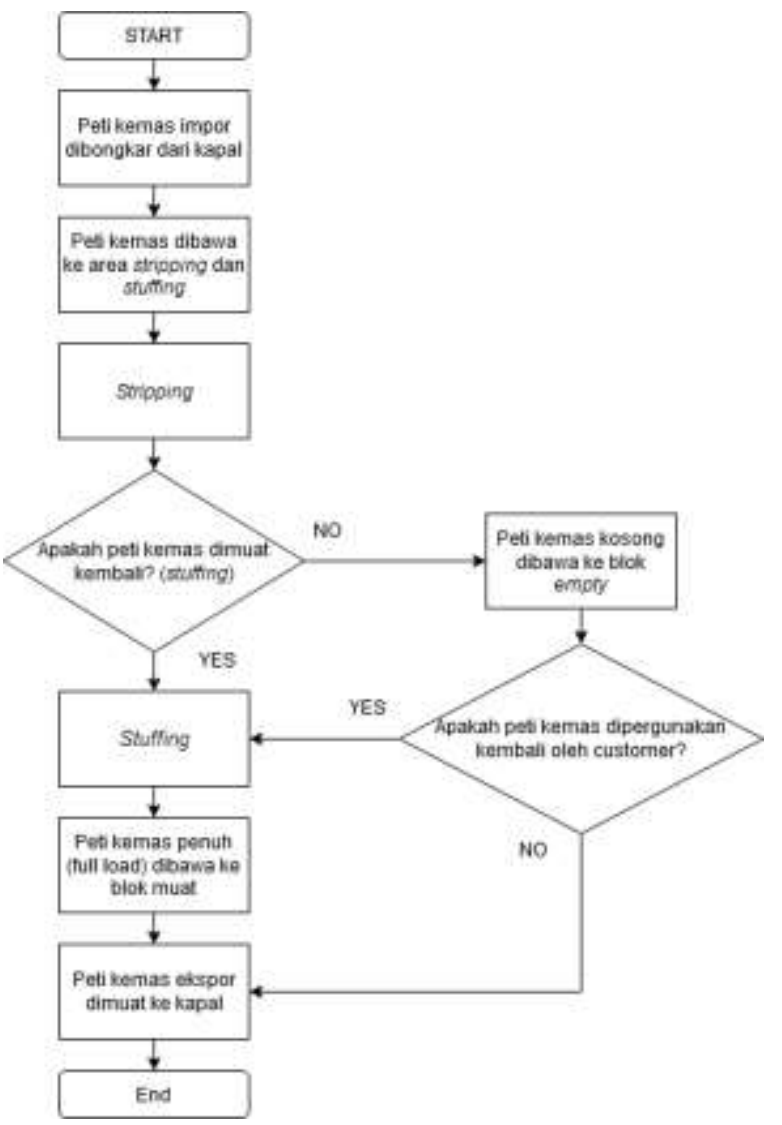

Gambar 5. Proses Penanganan Peti

\section{Kemas di Pelabuhan}

\section{Hasil dan Pembahasan}

a. Analisis Kondisi Pelabuhan Sorong

Hasil dari observasi dan wawancara yang dilakukan dalam penelitian ini dapat dirumuskan dalam sebuah diagram fishbone. Diagram fishbone pada Gambar 6 menunjukkan lima penyebab utama dari permasalahan pada Pelabuhan Sorong. Gambar tersebut menunjukkan adanya beberapa penyebab permasalahan dalam Pelabuhan Sorong. Akan tetapi, penelitian ini fokus pada salah satu akar pemasalahan yaitu belum tertatanya lapangan penumpukan sehingga menyebabkan rendahnya efisiensi penggunaan lapangan penumpulan peti kemas. Hal inilah yang melandasi penelitian ini.

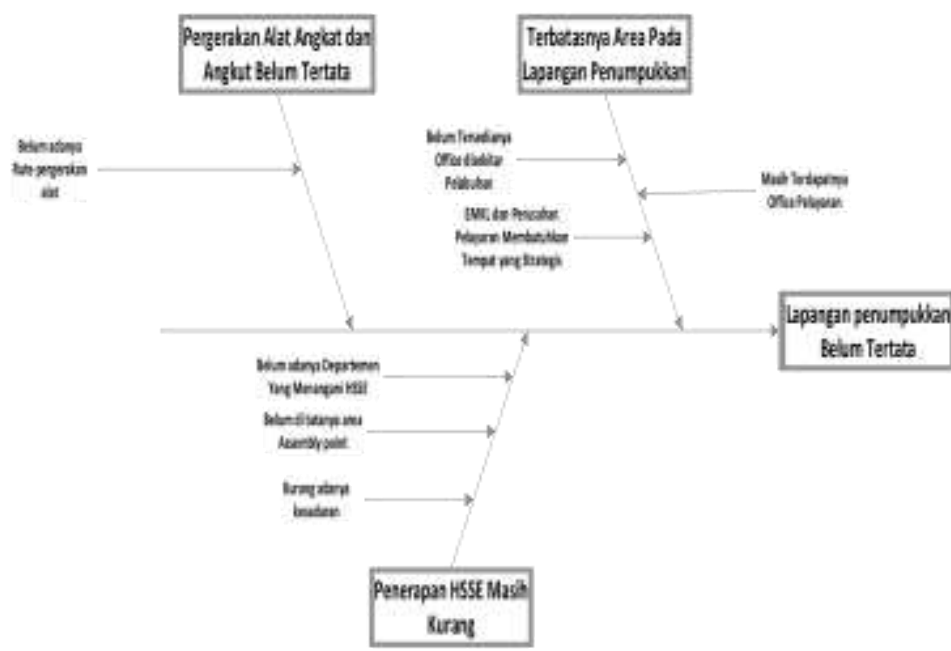

Gambar 6. Analisis Fishbone untuk Mengidentifikasi Permasalahan di Pelabuhan Sorong

- Penyebab 1: Terbatasnya lahan pada lapangan penumpukan

Terbatasnya area untuk lapangan penumpukkan pada Pelabuhan Sorong sangat berdampak pada

Judul Artikel: Perancangan Tata Letak Lapangan Penumpukan Peti Kemas (Studi Kasus: 
kegiatan operasional yang melibatkan pihak perusahaan pelayaran, Ekspedisi Muatan Kapal Laut (EMKL), dan Pelabuhan Sorong itu sendiri. Lokasi kantor perusahaan pelayaran yang berada di area lapangan penumpukkan juga membuat pengunaan lapangan lini 1 menjadi kurang efektif karena masih harus berbagi tempat dengan kantor perusahaan pelayaran. Selain itu, penempatan lokasi stuffing dan stripping pada lapangan penumpukan seharusnya berada pada area terpisah (Gambar 7). Hal ini bertujuan untuk memaksimalkan pergerakan alat, membuat area lini 1 tetap steril dari truk-truk EMKL.

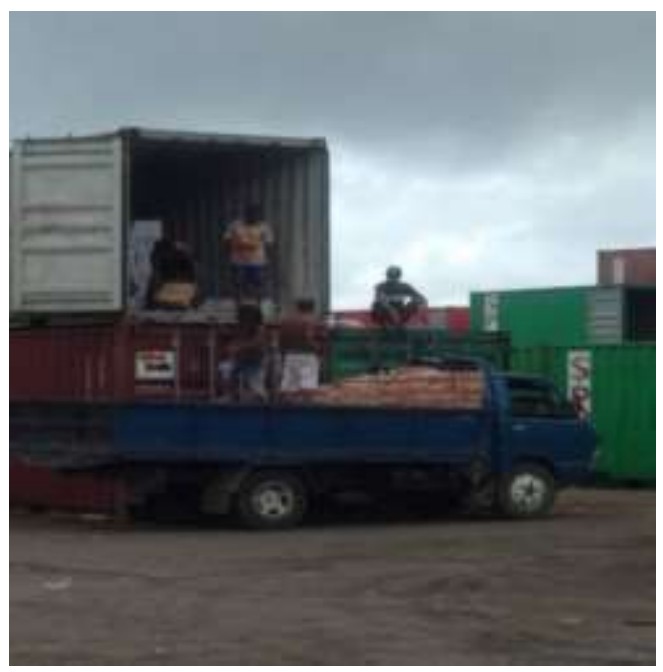

\section{Gambar 7. Aktivitas Stripping di}

\section{Area Lapangan Penumpukan}

- Penyebab 2: Pergerakan alat angkat dan angkut belum tertata

Pergerakan alat angkat dan angkut pada Pelabuhan Sorong masih belum memiliki alur yang tertata dimana pergerakan alat dan angkut sering kali saling berpapasan yang dapat membahayakan operator dari alat tersebut dan juga alat tersebut itu sendiri. Gambar 8 mengilustrasikan kegiatan angkut dan angkat di lapangan penumpukan.

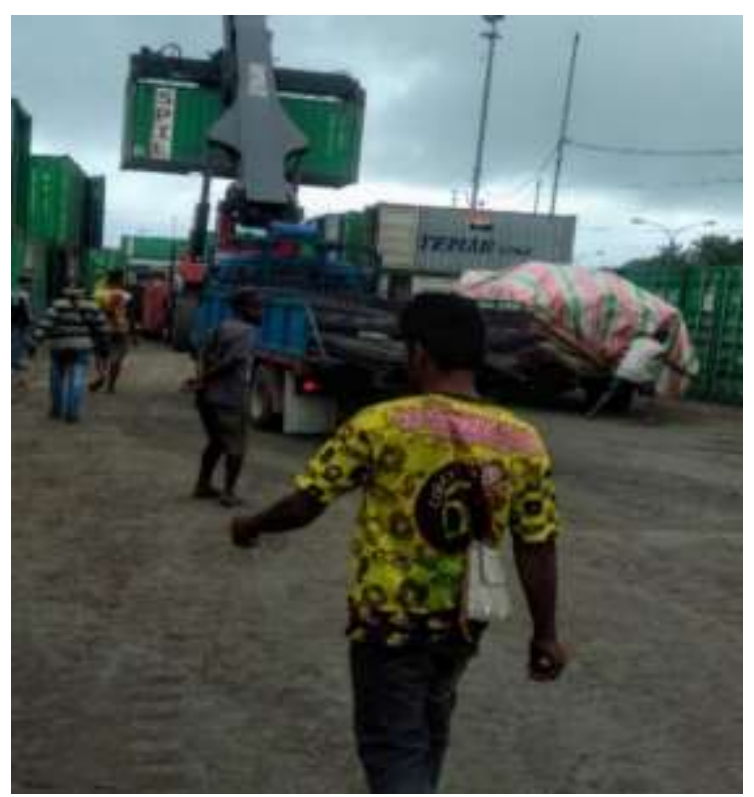

Gambar 8. Aktivitas Penanganan

Peti Kemas pada Lapangan Penumpukkan

Judul Artikel: Perancangan Tata Letak Lapangan Penumpukan Peti Kemas (Studi Kasus: 
- Penerapan prosedur keselamatan masih kurang

Pelabuhan Sorong belum memiliki fungsi khusus yang berfokus dalam hal penerapan prosedur keselamatan, sehingga faktor keselamatan di Pelabuhan Sorong masih sangat kurang diperhatikan. Salah satu contohnya adalah belum adanya assembly point di lapangan penumpukan yang akan dibutuhkan sebagai tempat berkumpul apabila terjadi hal-hal darurat seperti bencana alam. Pengunjung maupun pekerja yang memasuki lapangan lapangan lini 1 juga belum dilengkapi dengan alat pelindung diri seperti helm, sepatu keselamatan dan juga rompi yang berguna untuk menjaga keselamatan diri.

a. Hasil Peramalan Jumlah Peti Kemas Hasil peramalan jumlah peti kemas pada Pelabuhan Sorong dirangkum dalam Tabel 2. Tabel tersebut menunjukkan perbandingan nilai MAPE antar metode peramalan yang digunakan. Metode peramalan dengan nilai MAPE terkecil digunakan untuk memprediksi data jumlah peti kemas tahun 2019 sampai dengan tahun 2030.
Hasil dari peramalan ditunjukkan dalam Gambar 9.

Tabel 2. Hasil Peramalan Jumlah

Peti Kemas di Pelabuhan Sorong (MAPE)

Metode

Komponen Peramalan

Siklis

Tren

Siklis

\section{A. Bongkar}

Peti kemas berisi, ukuran 20 feet

0.07

0.04

Peti kemas berisi, ukuran 40 feet

$4.05 \quad 0.07$

Peti kemas kosong, ukuran 20 feet

$0.22 \quad 0.07$

Peti kemas kosong, ukuran 40 feet

\section{B. Muat}

Peti kemas berisi, ukuran 20 feet

0.14

Peti kemas berisi, ukuran 40 feet

0.66

Peti kemas kosong, ukuran 20 feet

Peti kemas kosong, ukuran 40 feet

Judul Artikel: Perancangan Tata Letak Lapangan Penumpukan Peti Kemas (Studi Kasus: 


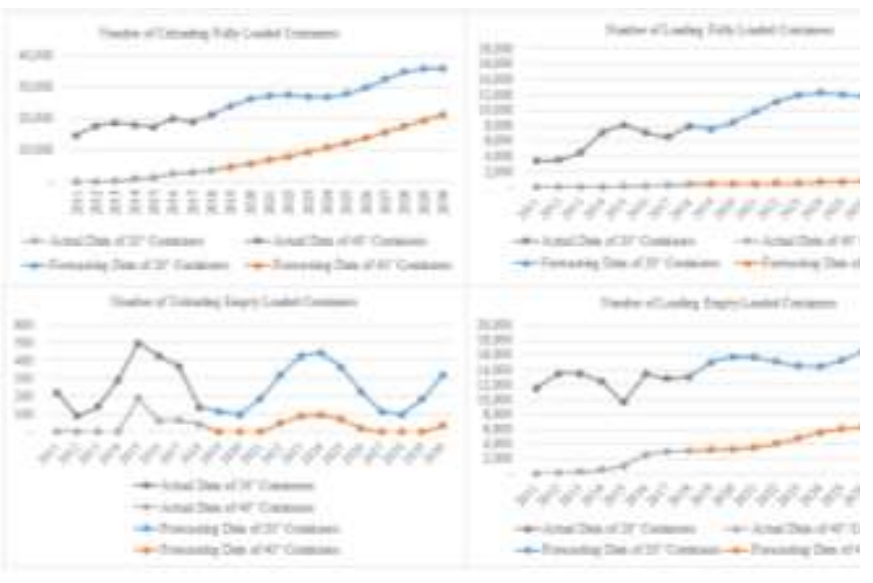

Gambar 9. Grafik Hasil Peramalan

Data Lalu Lintas Peti Kemas pada Pelabuhan Sorong

b. Hasil dan Analisa Perancangan Tata Letak Lapangan penumpukan

Berdasarkan hasil pengamatan dan perkiraan kebutuhan lapangan penumpukan di masa depan, penelitian ini merancang sebuah tata letak lapangan penumpukan di Pelabuhan Sorong. Gambar 10 menunjukkan kondisi lapangan penumpukan saat ini sedangkan Gambar 11 adalah tata letak lapangan penumpukan yang direkomendasikan.

Dalam menentukan luas area lapangan penumpukan, penelitian ini juga memperhatikan kebutuhan fasilitas penunjang utama yang harus tersedia di pelabuhan. Tabel 3 menunjukkan daftar fasilitas pendukung utama yang diperhitungkan dalam tata letak usulan beserta asumsi luas setiap fasilitas.
Fasilitas pos keamanan berfungsi untuk menjaga keamanan dan kelancaran pada lapangan penumpukan. Parkir mobil Pemadam Kebakaran (PMK) berfungsi sebagai sarana pencegahan dan penanggulangan kebakaran pada pelabuhan. Lokasi mobil PMK yang strategis membantu proses penanganan kecelakaan seperti kebakaran. Kantor dari perusahaan pelayaran berfungsi untuk mempermudah komunikasi dan pelayanan perusahaan pelayaran dengan Pelabuhan Sorong maupun EMKL. Tempat parkir mobil dan truk ditambahkan agar kendaraankendaraan tersebut memiliki area tersendiri dan tidak mengganggu aktivitas operasional Pelabuhan.

\section{Tabel 3. Fasilitas Pendukung Utama}

\begin{tabular}{|c|c|c|c|c|c|}
\hline \multirow{2}{*}{ Fasilitas } & \multirow{2}{*}{ Jumlah } & \multicolumn{2}{|c|}{ Ukur an (m) } & \multirow{2}{*}{$\begin{array}{c}\text { Luas } \\
\text { Fasilitas }\left(\mathrm{m}^{2}\right)\end{array}$} & \multirow{2}{*}{$\begin{array}{c}\text { Total luas } \\
\left(\mathrm{m}^{2}\right)\end{array}$} \\
\hline & & $\mathrm{P}$ & $\mathrm{L}$ & & \\
\hline Pos keamanan & 1 & 3,7 & 6 & 22,2 & 22,2 \\
\hline Parkir mobil PMK & 2 & 8 & 5 & 40 & 80 \\
\hline Kantor Perusahaan Pelayaran 1 & 1 & 6 & 5 & 30 & 30 \\
\hline Kantor Perusahaan Pelayaran 2 & 1 & 6 & 5 & 30 & 30 \\
\hline Kantor Perusahaan Pelayaran 3 & 1 & 6 & 5 & 30 & 30 \\
\hline Kantor Perusahaan Pelayaran 4 & 1 & 6 & 5 & 30 & 30 \\
\hline Parkir mobil & 1 & 5 & 15 & 75 & 75 \\
\hline
\end{tabular}

Tata letak lapangan penumpukan yang direkomendasikan dalam penelitian ini membagi lapangan penumpukan peti kemas menjadi tiga blok utama yaitu blok bongkaran, blok konsolidasi, serta blok open stack (Gambar 10). Alasan pengelompokan menjadi tiga blok

Judul Artikel: Perancangan Tata Letak Lapangan Penumpukan Peti Kemas (Studi Kasus: 
didasarkan pada pola operasi peti kemas pada Pelabuhan Sorong, seperti yang telah diidentifikasi sebelumnya pada Gambar 5. Rancangan ini mengubah pola pada Pelabuhan Sorong dari yang sebelumnya berdasarkan perusahaan pelayaran dan sekarang berdasarkan aktivitas pada lapangan penumpukan. Area untuk kegiatan stripping dan stuffing tidak dipertimbangkan dalam tata letak ini karena pada kondisi saat ini, kegiatan tersebut dilakukan di area yang berbeda (di luar terminal Pelabuhan Sorong).

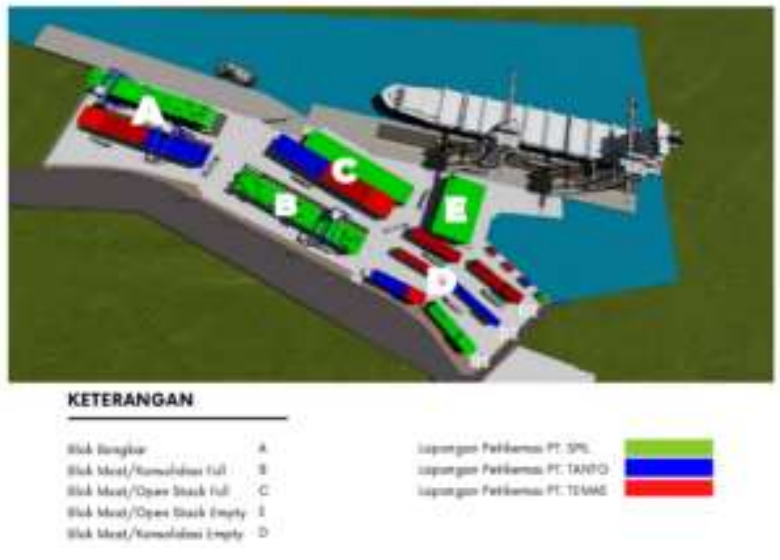

Gambar 10. Rekomendasi Tata

\section{Letak Lapangan Penumpukan di}

\section{Pelabuhan Sorong}

Tabel 4 merupakan hasil perhitungan jumlah peti kemas yang dapat disimpan pada lapangan penumpukan dengan tata letak yang direkomendasikan. Perhitungan tersebut adalah untuk peti kemas berukuran 20 feet dengan asumsi untuk peti kemas berukuran 40 feet akan menggunakan 2 kali kapasitas peti kemas 20 feet. Pada tata letak yang direkomendasikan, maksimum. penumpukan peti kemas disesuaikan dengan peralatan yang digunakan. Pada blok A dan B, maksimum penumpukan adalah lima tier, karena area ini menggunakan rubber tyred gantry crane. Sedangkan maksimum penumpukan pada blok $\mathrm{C}$ dan $\mathrm{D}$ adalah empat tier, karena area ini menggunakan reach stacker.

\section{Tabel 4. Rekapitulasi Jumlah Peti}

Kemas

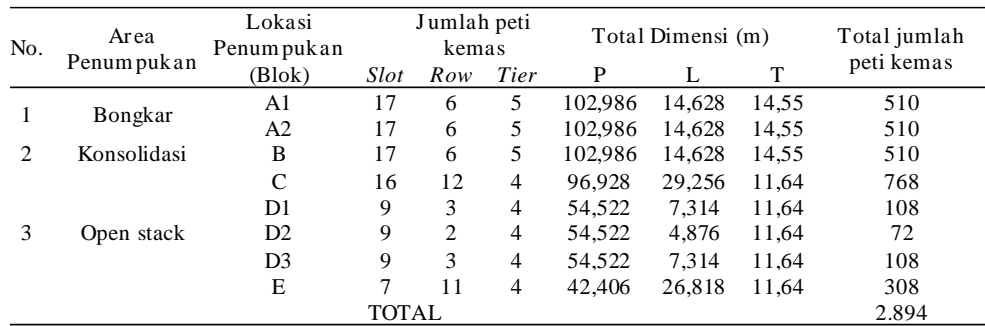

(Ukuran peti kemas: 6,058 x 2,438 x $2,91 \mathrm{~m})$

Dari perhitungan, total peti kemas yang dapat disimpan dalam lapangan penumpukan adalah sebanyak 2.894 buah peti kemas berukuran 20 feet dengan rincian 1.020 peti kemas di area blok bongkar, 510 peti kemas pada area blok konsolidasi, dan 1.364 peti kemas pada area blok open stack.

Judul Artikel: Perancangan Tata Letak Lapangan Penumpukan Peti Kemas (Studi Kasus: 
Jumlah peti kemas yang dapat ditampung pada blok bongkaran ini untuk saat ini masih cukup karena kenaikan jumlah peti kemas yang ada belum terlalu signifikan. Pergerakan peti kemas pada blok bongkaran ini tergolong cepat karena adanya pengoperasian inland container depot pada Pelabuhan Sorong.

Blok konsolidasi tidak banyak menampung peti kemas, karena peti kemas pada blok ini biasanya tidak disimpan terlalu lama. Peti kemas pada blok ini adalah peti kemas yang sedang menunggu penunjukan kapal untuk dilakukan pemuatan peti kemas. Kapasitas penampungan peti kemas pada blok open stack cukup tinggi agar dapat untuk menampung peti kemas dalam jumlah banyak. Hal ini disebabkan oleh sering terjadinya aktivitas pemuatan peti kemas ke kapal dalam waktu yang bersamaan.

Tabel 5. Perhitungan YOR Tahun 2019 - 2030 dengan Tata Letak Baru

\begin{tabular}{ccc}
\hline Tahun & Prediksi lalu lintas peti kemas (TEU) & YOR \\
\hline 2019 & $55.326,25$ & $52,38 \%$ \\
2020 & $60.284,21$ & $57,07 \%$ \\
2021 & $64.210,04$ & $60,79 \%$ \\
2022 & $66.947,14$ & $63,38 \%$ \\
2023 & $69.023,05$ & $65,34 \%$ \\
2024 & $71.430,63$ & $67,62 \%$ \\
2025 & $75.025,59$ & $71,03 \%$ \\
2026 & $80.024,25$ & $75,76 \%$ \\
2027 & $85.900,29$ & $81,32 \%$ \\
2028 & $91.627,45$ & $86,74 \%$ \\
2029 & $96.322,08$ & $91,19 \%$ \\
2030 & $99.816,27$ & $94,50 \%$ \\
\hline
\end{tabular}

Dengan menggunakan hasil prediksi lalu lintas peti kemas, YOR Pelabuhan Sorong dengan kapasitas penyimpanan di tata letak yang baru dapat dihitung. Tabel 5 menunjukkan hasil perhitungan prediksi YOR Pelabuhan Sorong pada tahun 2019 sampai dengan 2030. Sesuai dengan Keputusan Direktur Jenderal Perhubungan Laut Nomor UM. 002/38/13/18/DJPL-11 tentang Standar Kinerja Pelayanan Operasional Pelabuhan, standar utilitas YOR di Pelabuhan Sorong adalah 70\% ([Kemenhub], 2011). Sedangkan berdasarkan hasil perhitungan, usulan tata letak dapat memenuhi kebutuhan lapangan penumpukan sampai dengan tahun 2025 dengan nilai YOR mencapai 71,03\%. Kemudian pada tahun 2027, YOR Pelabuhan Sorong diperkirakan mencapai $81,32 \%$. Nilai YOR yang cukup besar, menandakan bahwa lapangan penumpukan mulai menangani jumlah peti kemas lebih dari kapasitasnya, sehingga berpotensi terjadinya congestion (antrian) pada berbagai pos operasi di pelabuhan. Oleh karena itu, mulai tahun 2027, Pelabuhan Sorong disarankan untuk menambah kapasitas lapangan penumpukannya dengan perluasan lahan atau pemutakhiran alat penanganan material.

Judul Artikel: Perancangan Tata Letak Lapangan Penumpukan Peti Kemas (Studi Kasus: 


\section{Simpulan}

Pelabuhan Sorong merupakan gerbang perekonomian di Papua Barat dan memegang peran penting dalam menangani aktivitas ekspor dan impor barang di daerah tersebut. Seiring dengan berkembangnya perekonomian di Indonesia timur, jumlah permintaan kargo selalu bertambah sehingga pergerakan arus peti kemas di Pelabuhan Sorong kian meningkat tiap tahunnya. Kelancaran penanganan peti kemas di sebuah pelabuhan sangat bergantung pada efisiensi alur pergerakan penanganan peti kemas di terminal, sehingga manajemen Pelabuhan Sorong juga perlu memperhatikan rancangan tata letak lapangan penumpukan sembari memaksimalkan utilitasnya sesuai dengan standar kinerja pelabuhan. Oleh karena itu, penelitian ini bertujuan untuk mengusulkan rancangan tata letak lapangan penumpukan Pelabuhan Sorong, dengan memperhatikan alur operasi penanganan peti kemas dan ramalan permintaan jumlah peti kemas sampai dengan tahun 2030. Hasil dari penelitian ini diharapkan dapat menjadi salah satu masukan untuk pihak manajemen Pelabuhan Sorong dalam memperbaiki tata letak penumpukan peti kemas agar dapat mengakomodir jumlah permintaan yang kiat meningkat.

Pengumpulan data dilaksanakan berdasarkan wawancara, observasi lapangan serta data historis yang dikeluarkan oleh pelabuhan. Usulan tata letak penumpukan peti kemas dirancang dengan mengidentikasi fasilitas-fasilitas yang dibutuhkan pelabuhan dan alur operasi peti kemas sesuai dengan yang saat ini diterapkan di Pelabuhan Sorong. Hasil rancangan tata letak dievaluasi untuk mengetahui tingkat utilitasnya sesuai dengan ramalan jumlah peti kemas sampai dengan tahun 2030 menggunakan rumus YOR. Berdasarkan hasil perhitungan, diperoleh bahwa usulan tata letak penumpukan peti kemas dapat mengakomodir jumlah peti kemas di Pelabuhan Sorong dengan utilitas yang baik yaitu YOR 71,03\% pada tahun 2025 . Namun, pada tahun 2027, ramalan menunjukkan nilai YOR mencapai $81,32 \%$, dimana nilai ini menunjukkan lebih dari penetapan standar kinerja Pelabuhan Sorong sebesar 70\%, sehingga perluasan lapangan penumpukan dapat menjadi solusi ke depannya. 


\section{E. Daftar Pustaka}

[Kemenhub]. (2011). Keputusan Direktur

Jenderal Perhubungan Laut Nomor UM.002/38/13/18/DJPL tentang Standar Kinerja Pelayanan Operasional Pelabuhan. Jakarta: Kemenhub RI

Ariyanto, D. (2018). Pengaruh Depo Lini Dua untuk Mengoptimalkan Waktu Tunggu Tiga Hari di Pelabuhan. Jurnal Penelitian Transportasi Laut, 20(2), 109-119.

Mappangara, A. S. C., Samang, L., Adisasmita, R., \& Sitepu, G. Optimization Container Yard Capacity Of Pantoloan Port in 2020 to Support Corridor Sulawesi Connectivity.

Pakpahan, H. M. (2019). Evaluasi Kinerja Yard Occupancy Ratio (YOR)
Pelabuhan Tenau, Kupang. ReTII, 449 456-449 456.

Somadi, S., Permatasari, I. D., \& Chintia, R. J. J. L. I. (2020). Pengukuran Kapasitas Container Yard Menggunakan Yard Occupancy Ratio dalam Upaya Optimalisasi Penggunaan Lapangan Penumpukan Kontainer di PT XYZ. 4(1), 1-11.

Timur, H. Z. (2016). Evaluation On Container Products In East Nilam Terminal, Tanjung Perak Port. Paper presented at the Journal of the Civil Engineering Forum Vol.

Triatmodjo, B. (2011). Perencanaan Pelabuhan. Yogyakarta: Beta Offset.

Triatmodjo, B. J. B. O. Y. (2010). Perencanaan pelabuhan. 490. 
Judul Artikel: Perancangan Tata Letak Lapangan Penumpukan Peti Kemas (Studi Kasus:

Pelabuhan Sorong) 